\title{
Multiple myelomatosis: an unusual cause of small bowel intussusception
}

\author{
S.A. Hill and P.L. Yudelman \\ Department of General Surgery, Northampton General Hospital, Billing Road, Northampton NN1 5BD, UK.
}

\begin{abstract}
Summary: A 55 year old woman with multiple myeloma presented with a pathological fracture of the right neck of femur. Following internal fixation, and during subsequent radiotherapy, she developed small bowel obstruction. Laparotomy revealed an intussusception about a small bowel myeloma deposit. This is a previously unreported cause of small bowel intussusception.
\end{abstract}

\section{Introduction}

Multiple myeloma may be defined as a moderately well differentiated neoplastic disorder of B lymphoid cells, in which the predominant cell type is a plasma cell. The annual incidence in Europe is approximately 3 per 100,000 population. The pathological process is usually confined to bone-marrow, but rarely may metastasize to involve other organs. We report a case of dissemination to small bowel causing intestinal obstruction.

\section{Case report}

A 55 year old woman presented with hip pain. An Xray of the right hip demonstrated a lytic lesion in the lesser trochanter. Other investigations revealed an erythrocyte sedimentation rate of $30 \mathrm{~mm} / \mathrm{h}$, monoclonal IgA band on protein electrophoresis and normal total gammaglobulin. Urinary Bence Jones protein was absent, and marrow aspirate showed atypical plasma cells. She underwent internal fixation of her right hip at which time trephine biopsy was performed. This revealed markedly increased plasma cells and positive IgA monoclonal immunoperoxidase staining. She was referred to Northampton General Hospital for radiotherapy to the hip, during which she developed increasing abdominal distension and vomiting. She failed to settle, clinically and radiologically, and underwent laparotomy.

An obstructing intussusception of mid-small bowel was found, with a subserosal mass at its apex. The proximal bowel was grossly distended, with empty ileum distally. The mucosal mass, which was macroscopically pale, measured $3.5 \mathrm{~cm}$ in diameter, extending

Correspondence: S.A. Hill, M.A., B.M., B.Ch.

Accepted: 16 June 1986 through to the serosa. The affected segment was resected and a primary end-to-end anastomosis performed. Subsequent histology showed a small bowel plasmacytoma. The patient made a good postoperative recovery.

\section{Discussion}

Soft tissue plasmacytomas have been described affecting most parts of the body, either as secondary deposits from generalized myeloma, or as primary lesions in the condition of extramedullary plasmacytoma. The latter is defined as a plasma cell aggregate in a circumscribed tumour of variable size and location other than in bone marrow. The relationship of extramedullary plasmacytoma to multiple myeloma has been reviewed by Wiltshaw (1976).

The occurrence of extramedullary lesions in multiple myeloma was investigated by Pasmantier \& Azar (1969) who reported a $65 \%$ incidence of extramedullary lesions in 57 cases. This was, however, based on the evidence of microscopic features at autopsy, and the occurrence of overt extramedullary lesions in multiple myeloma is rare during the patient's lifetime. Moreover, when such lesions do occur, the site of involvement is rarely the gastrointestinal tract. Hayes et al. (1952) found only five cases of intestinal involvement in a review of 182 cases of myeloma with extramedullary involvement.

Goldstein \& Poker (1966) described the first case of disseminated myeloma in which radiological signs of gastrointestinal involvement were observed during the clinical course, while Elias et al. (1969) reported two cases of large bowel obstruction in multiple myeloma. Our patient is of interest because she fulfils the criteria for the diagnosis of multiple myeloma, and presents

(C) The Fellowship of Postgraduate Medicine, 1986 
the rare complication of gastrointestinal involvement leading to intussusception and small bowel obstruction. Although large and small bowel intussusception have been reported following a diagnosis of primary

\section{References}

BUDD, D.C., COCHRAN, R.C. \& METILDI, L.A. (1977). Extramedullary plasmacytoma of the colon, a rare cause of intussusception. American Surgeon, 43 (8), 528.

ELIAS, E.G., GAILANI, S., JONES, R. \& MITTELMAN, A. (1969). Extraosseous multiple myeloma: a cause of intestinal obstruction. Annals of Surgery, 170, 857.

FISHER, B. \& KLEIN, D.L. (1975). Metastasizing plasma cell tumour of small bowel. American Journal of Gastroenterology, 64 (5), 371.

GOLDSTEIN, W.B. \& POKER, N. (1966). Multiple myeloma extramedullary plasmacytoma (Fisher \& Klein, 1975; Budd et al., 1977), this complication has not been previously reported in generalized myeloma with marrow involvement.

involving the gastrointestinal tract. Gastroenterology, $\mathbf{5 1}$ 87.

HAYES, D.W., BENNETT, W.A. \& HECK, F.J. (1952). Ex- ळ tramedullary lesions in multiple myeloma. Archives of $\overrightarrow{0}$ Pathology, 53, 262.

PASMANTIER, M.W. \& AZAR, H.A. (1969). Extraskeletal spread in multiple plasma cell myeloma. Cancer, 23, 167. WILTSHAW, E. (1976). The natural history of extramedullary plasmacytoma and its relation to solitary myeloma of bone $\exists$ and myelomatosis. Medicine, 55 (3), 217. 